\title{
UJI EFEK ANTIMIKROBA EKSTRAK DAUN PUTRI MALU (MIMOSA PUDICA DUCHAAS \& WALP) SECARA IN VITRO
}

\author{
Lieken Mehingko \\ Henoch Awaloei \\ Mona P.Wowor
}

\author{
Bagian Farmakologi dan Terapi Fakultas Kedokteran Universitas Sam Ratulangi Manado \\ Email: liekenartarini@yahoo.com \\ awaloeihenoch@yahoo.com
}

\begin{abstract}
The "sensitive plant" (Mimosa pudica Duchaas \& Walp) is categorized as a spreading weed. Its existence is threatened due to the assumption that it has no positive qualities. However, parts of this plant, including roots, stems, and leaves, either fresh or dried, have been used as a traditional medicine. Based on the benefits of this plant in conjunction with increases of infectious diseases due to microbes, research into the antimicrobial effects of the extract of this plant in vitro has to be developed much more. The result of this study was that antimicrobial effects of this "sensitive" plant's leaf extract, at a concentration of $100 \%$, was more effective than at concentrations of $50 \%$ or $33 \%$, based on the diameters of the zones of inhibition where no microbes grew.
\end{abstract}

Keywords: antimicrobial, in vitro, Mimosa pudica Duchaas \& Walp

\begin{abstract}
Abstrak: Tumbuhan Putri malu (Mimosa pudica Duchaas \& Walp) tergolong rumput liar yang terancam keberadaannya karena sering dianggap gulma yang merugikan tanaman budidaya. Seluruh bagian tanaman ini dapat berkhasiat sebagai obat mulai dari akar, batang, dan daun, baik dalam bentuk segar ataupun yang dikeringkan. Berdasarkan manfaat dari tumbuhan putri malu serta semakin meningkatnya penyakit infeksi yang disebabkan oleh bakteri maka perlu dilakukan penelitian uji efek antimikroba dari ekstrak daun putri malu secara in vitro. Hasil penelitian memperlihatkan efek antimikroba ekstrak daun putri malu dengtan konsentrasi 100\% lebih efektif daripada konsentrasi 50\% dan 33\% dengan berpatokan pada panjangnya diameter zona hambat yang terbentuk oleh masing-masing bakteri uji.
\end{abstract}

Kata kunci: antimikroba, in vitro, putri malu

Obat tradisional adalah obat yang diolah secara tradisional, turun-temurun, berdasarkan resep nenek moyang, adat-istiadat, kepercayaan, atau kebiasaan setempat, baik bersifat magis maupun pengetahuan tradisional. ${ }^{1}$ Keuntungan penggunaan obat tradisional yaitu antara lain bahan bakunya mudah diperoleh dan harganya murah. Oleh karena itu masyarakat cenderung memilih pengobatan secara tradisional walaupun penggunaannya sampai sekarang ini belum sepenuhnya didukung oleh penelitian ilmiah. ${ }^{2}$

Tumbuhan putri malu (Mimosa pudica
Duchaas \& Walp) merupakan salah satu contoh tumbuhan liar yang sering terancam keberadaannya karena dapat merugikan tanaman budidaya, sehingga umumnya masyarakat cenderung untuk memangkasnya dengan mengabaikan khasiatnya. ${ }^{3}$

Masyarakat bantaran kali Surabaya telah memanfaatkan ramuan akar putri malu sebagai obat rematik dengan cara mengompres bagian sendi yang sakit; juga digunakan oleh penderita penyakit jantung. Sama halnya dengan masyarakat Minangkabau yang telah menggunakan ramuan 
tumbuhan putri malu untuk pemakaian luar dengan cara tumbuhan segar digiling sampai halus lalu dibubuhkan pada bagian tubuh yang sakit, seperti luka, memar, dan radang kulit bernanah (pioderma). ${ }^{4} \mathrm{Di}$ Filipina, akarnya dipakai sebagai diuretik, yaitu dengan cara direbus dan diminum untuk memperlancar pengeluaran air seni. Di samping itu juga digunakan untuk pengobatan disentri dan penghilang rasa nyeri pada saat haid. Para ahli pengobatan Cina mengindikasikan putri malu untuk mengobati berbagai jenis penyakit seperti radang mata akut (konjungtivitis), kencing batu (urolitiasis), demam tinggi pada anak-anak, cacingan, insomnia, peradangan saluran napas (bronchitis), dan herpes zoster. Sebuah penelitian terdahulu telah berhasil mengisolasi dan mengidentifikasi senyawa yang terkandung dalam putri malu, yaitu senyawa flavonoid golongan flavon dan flavanol dalam ekstrak metanol daunnya.,

Pada saat ini semakin banyak obat antimikroba yang dikembangkan dengan berbagai macam kegunaan dan efek sampingnya. Di samping itu, dengan semakin meningkatnya resistensi terhadap obat antimikroba serta harga obat yang mahal, maka diperlukan penelitian dan pengujian untuk menemukan bahan yang memiliki daya antimikoba yang aman, berkhasiat, murah, dan mudah diperoleh.

Tujuan penelitian ini adalah untuk mengetahui ada tidaknya daya antimikroba dari ekstrak daun putri malu (Mimosa pudica duchaas \& walp) terhadap beberapa jenis

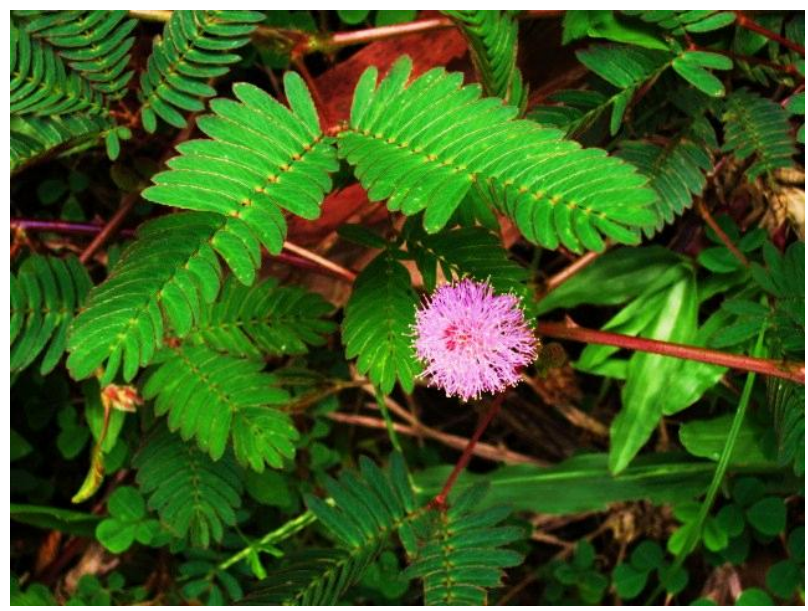

Putri malu (Mimosa pudica Duchaas \& Walp) bakteri penyebab penyakit infeksi. Penelitian ini menggunakan metode pengujian Kirby-Bauer atau diffusion test.

\section{BAHAN DAN METODE}

\section{Persiapan ekstraksi sampel}

Bahan sampel berupa daun putri malu segar dibersihkan kemudian dikeringkan dalam oven selama satu hari dengan suhu $37^{0}$. Setelah kering daun putri malu dibuat menjadi serbuk dengan menggunakan blender. Serbuk yang telah halus ditimbang sebanyak 100 gram kemudian dilarutkan dalam pelarut etanol $80 \%$ sebanyak 1000 $\mathrm{ml}$, kemudian ditambahkan $200 \mathrm{ml}$ akuades. Larutan dibiarkan selama satu minggu sambil diaduk selama 15 menit setiap hari. Selanjutnya larutan disaring dengan menggunakan kertas saring untuk menghasilkan filtrat. Hasil saringan dituang kedalam cawan petri lalu dikeringkan selama \pm dua hari dengan suhu $37^{0}$ untuk menguapkan etanol sehingga dengan demikian diperoleh ekstrak daun kering.

Pembuatan larutan uji dengan berbagai tingkat konsentrasi yaitu: $100 \%, 50 \%$, dan $33 \%$, diperoleh dari 1 gram ekstrak daun kering ditambahkan masing-masing akuades sebanyak $1 \mathrm{ml}, 2 \mathrm{ml}$, dan $3 \mathrm{ml}$.

\section{Pembuatan larutan antibiotik pemban- ding}

Penelitian ini menggunakan dua jenis antibiotik sebagai kontrol positif yaitu siprofloksasin untuk bakteri gram negatif dan sefadroksil untuk bakteri gram positif.

Kapsul sefadroksil $500 \mathrm{mg}$ dibuka kemudian bubuk sefadroksil dilarutkan ke dalam $125 \mathrm{ml}$ akuades steril sehingga diperoleh larutan antibiotik dengan konsentrasi $500 \mathrm{mg} / 125 \mathrm{ml}=4 \mathrm{mg} / \mathrm{ml}$. Diambil $1 \mathrm{ml}$ larutan sefadroksil kemudian ditambahkan dengan $1 \mathrm{ml}$ akuades steril sehingga terdapat larutan $4 \mathrm{mg} / 2 \mathrm{ml}=2 \mathrm{mg} / \mathrm{ml}$ atau $2000 \mu \mathrm{g} / \mathrm{ml}$.

Tablet siprofloksasin $500 \mathrm{mg}$ dilarutkan ke dalam $125 \mathrm{ml}$ akuades steril sehingga diperoleh larutan antibiotik dengan 
konsentrasi $500 \mathrm{mg} / 125 \mathrm{ml}=4 \mathrm{mg} / \mathrm{ml}$. Diambil $1 \mathrm{ml}$ larutan siprofloksasin kemudian ditambahkan dengan $1 \mathrm{ml}$ akuades steril sehingga terdapat larutan $4 \mathrm{mg} / 2 \mathrm{ml}=$ $2 \mathrm{mg} / \mathrm{ml}$ atau $2000 \mu \mathrm{g} / \mathrm{ml}$.

\section{Peremajaan bakteri dan penanaman lapisan pembenihan}

Bakteri yang digunakan dalam penelitian ini adalah Escherichia coli, Staphylococcus aureus, Enterobacter cloacae, Pseudomonas aeruginosa, Proteus stuarti. Bakteri-bakteri ini diperoleh dari persediaan yang disimpan di Laboratorium Riset Biomedik Fakultas kedokteran UNSRAT Manado. Dari ke lima jenis bakteri ini, hanya Staphylococcus aureus yang tergolong bakteri positif, sehingga kontrol (+) yang digunakan untuk bakteri ini adalah antibiotika sefadroksil. Mula-mula dilakukan peremajaan dengan menanam bakteri-bakteri tersebut ke dalam media NA (Nutrient Agar). Setelah itu diinkubasi pada suhu $37^{\circ} \mathrm{C}$ selama 24 jam. Selanjutnya koloni diambil dari media NA dan dimasukkan ke dalam tabung reaksi yang berisi Brainheart Infusion (BHI) sebagai suspensi bakteri sampai kekeruhannya sama dengan standar Mc Farland. Dengan menggunakan lidi kapas steril, diambil kuman dari suspensi bakteri kemudian ditanamkan pada lapisan pembenihan (Muller Hinton Agar), dimana pada permukaan lapisan pembenihan telah dibuat lima sumur sedemikian rupa sehingga berjarak sama satu dengan lainnya.

\section{Pengujian aktivitas antimikroba secara in vitro}

Pada setiap sumur diteteskan sebanyak $50 \mu \mathrm{l}$ dari larutan uji, kontrol positif, dan kontrol negatif, yaitu masing-masing ekstrak daun putri malu konsentrasi $100 \%$, $50 \%$ dan $33 \%$, larutan antibiotik, dan akuades steril dengan menggunakan mikropipet $50 \mu 1$. Kemudian diinkubasi di dalam inkubator pada suhu $37^{\circ} \mathrm{C}$ selama $16-24$ jam. Interpretasi hasil pengujian dapat dilihat setelah diinkubasi, yaitu adanya wilayah bening atau zona hambat disekitar media pertumbuhan bakteri yang merupakan tanda kepekaan bakteri terhadap ekstrak daun putri malu dan antibiotik sebagai kontrol positif. Tingkat kepekaannya dinyatakan dengan panjang diameter dari zona hambat.

\section{HASIL PENELITIAN}

Pada penelitian ini dilakukan sebanyak tiga kali percobaan untuk ke lima jenis bakteri uji. Hasil pengujian efek antimikroba ekstrak daun putri malu (Mimosa pudica duchaas \& walp) terhadap penghambatan aktivitas tumbuh ke lima jenis bakteri uji setelah dilakukan inkubasi selama 16 jam dapat dilihat pada Tabel 1-5.

Tabel 1. Hasil pengujian efek antimikroba ekstrak daun putri malu terhadap penghambatan aktivitas tumbuh Pseudomonas aeruginosa

\begin{tabular}{ccccccc}
\hline & \multicolumn{3}{c}{ D I A M E T E R } & Z O N E & H A M B A T* \\
\cline { 2 - 4 } PERCOBAAN & \multicolumn{3}{c}{ Ekstrak putri malu } & Siprofloksasin & $\begin{array}{c}\text { Akuades } \\
\text { (kontrol +) }\end{array}$ & (kontrol -) \\
\cline { 2 - 4 } & $33 \%$ & $50 \%$ & $100 \%$ & 21 & 34 & - \\
I & - & 11 & 25 & 40 & - \\
II & - & 18 & 23 & 38 & - \\
Rata-rata & - & 14 & 23 & 37 & - \\
\hline
\end{tabular}

Keterangan : *Angka dalam satuan milimeter dengan diameter sumur 5 milimeter

Tabel 1 memperlihatkan bahwa ekstrak daun putri malu menunjukkan hasil yang positif dengan adanya zona hambat yang terbentuk pada konsentrasi 50\% dan 100\% terhadap bakteri uji Pseudomonas aeruginosa meskipun diameter rataan antibiotik jauh lebih besar dibandingkan ekstrak daun putri malu. 
Tabel 2. Hasil pengujian efek antimikroba ekstrak daun putri malu terhadap penghambatan aktivitas tumbuh Enterobacter cloacae

\begin{tabular}{cccccc}
\hline \multirow{2}{*}{ PERCOBAAN } & \multicolumn{5}{c}{ DIAMETER ZONA HAMBAT* } \\
\cline { 2 - 4 } & $33 \%$ & $50 \%$ & $100 \%$ & Siprofloksasin & $\begin{array}{c}\text { Akuades } \\
{[\text { kontrol (+)] }}\end{array}$ \\
\cline { 2 - 5 }$[$ kontrol (-)] \\
\hline I & 10 & 15 & 26 & 30 & - \\
II & 9 & 14 & 24 & 27 & - \\
III & 9 & 11 & 22 & 26 & - \\
Rata-rata & 9 & 13 & 24 & 28 & - \\
\hline
\end{tabular}

Keterangan : *Angka dalam satuan milimeter dengan diameter sumur 5 milimeter

Berbeda dengan Tabel 1, pada Tabel 2 ekstrak daun putri malu telah menunjukkan adanya zona hambat mulai dari konsentrasi yang terendah terhadap bakteri uji Enterobacter cloacae, yaitu konsentrasi 33\%, walaupun diameter rataan ekstrak daun putri malu yang terbentuk hampir sama dengan yang terbentuk pada Tabel 1.

Tabel 3. Hasil pengujian efek antimikroba ekstrak daun putri malu terhadap penghambatan aktivitas tumbuh Staphylococcus aureus

\begin{tabular}{|c|c|c|c|c|c|}
\hline \multirow{3}{*}{ PERCOBAAN } & \multicolumn{5}{|c|}{ DIAMETER ZONA HAMBAT* } \\
\hline & \multicolumn{3}{|c|}{ Ekstrak putri malu } & \multirow{2}{*}{$\begin{array}{l}\text { Sefadroksil } \\
{[\text { kontrol }(+)]}\end{array}$} & \multirow{2}{*}{$\begin{array}{l}\text { Akuades } \\
{[\operatorname{kontrol}(-)]}\end{array}$} \\
\hline & $33 \%$ & $50 \%$ & $100 \%$ & & \\
\hline I & - & - & 14 & 35 & - \\
\hline II & - & - & 14 & 31 & - \\
\hline III & - & - & 11 & 30 & - \\
\hline Rata-rata & - & - & 13 & 32 & - \\
\hline
\end{tabular}

Keterangan : *Angka dalam satuan milimeter dengan diameter sumur 5 milimeter

Pada Tabel 3 zona hambat hanya tampak pada konsentrasi ekstrak daun putri malu $100 \%$, sedangkan pada konsentrasi $33 \%$ dan 50\% tidak tampak.

Tabel 4. Hasil pengujian efek antimikroba ekstrak daun putri malu terhadap penghambatan aktivitas tumbuh Escherichia coli

\begin{tabular}{|c|c|c|c|c|c|}
\hline \multirow{3}{*}{ PERCOBAAN } & \multicolumn{5}{|c|}{ DIAMETER ZONA HAMBAT* } \\
\hline & \multicolumn{3}{|c|}{ Ekstrak putri malu } & \multirow{2}{*}{$\begin{array}{l}\text { Siprofloksasin } \\
{[\text { kontrol }(+)]}\end{array}$} & \multirow{2}{*}{$\begin{array}{l}\text { Akuades } \\
{[\text { kontrol }(-)]}\end{array}$} \\
\hline & $33 \%$ & $50 \%$ & $100 \%$ & & \\
\hline I & - & - & 17 & 23 & - \\
\hline II & - & - & 14 & 22 & - \\
\hline III & - & - & 16 & 25 & - \\
\hline Rata-rata & - & - & 16 & 23 & - \\
\hline
\end{tabular}

Keterangan :*Angka dalam satuan millimeter dengan diameter sumur 5 milimeter

Sama halnya dengan pada Tabel 3, pada Tabel 4 zona hambat juga hanya tampak pada konsentrasi ekstrak putri malu $100 \%$. 
Tabel 5. Hasil pengujian efek antimikroba ekstrak daun putri malu terhadap penghambatan aktivitas tumbuh Proteus stuarti

\begin{tabular}{|c|c|c|c|c|c|}
\hline \multirow[b]{3}{*}{ PERCOBAAN } & \multicolumn{5}{|c|}{ DIAMETER ZONA HAMBAT* } \\
\hline & \multicolumn{3}{|c|}{ Ekstrak putri malu } & \multirow{2}{*}{$\begin{array}{l}\text { Siprofloksasin } \\
\text { [kontrol }(+)]\end{array}$} & \multirow{2}{*}{$\begin{array}{l}\text { Akuades } \\
{[\text { kontrol }(-)]}\end{array}$} \\
\hline & $33 \%$ & $50 \%$ & $100 \%$ & & \\
\hline $\mathbf{I}$ & - & 14 & 22 & 35 & - \\
\hline II & - & 15 & 22 & 33 & - \\
\hline III & - & 18 & 24 & 37 & - \\
\hline Rata-rata & - & 17 & 22 & 35 & - \\
\hline
\end{tabular}

Keterangan :*Angka dalam satuan milimeter dengan diameter sumur 5 milimeter

Tabel 5 memperlihatkan bahwa zona hambat terbentuk pada konsentrasi ekstrak putri malu 50\% dan $100 \%$ terhadap bakteri uji Proteus stuarti, meskipun diameter rataan zone inhibisi siprofloksasin [kontrol (+)] masih jauh lebih besar dibandingkan ekstrak daun putri malu.

\section{PEMBAHASAN}

Dalam penelitian ini, larutan ekstrak daun putri malu yang dibuat sebagai larutan uji dengan konsentrasi yang berbeda-beda yakni konsentrasi 100\%, 50\% dan 33\%. Hal ini bertujuan untuk melihat kadar minimum larutan uji yang masih efektif menghambat pertumbuhan bakteri (Minimum inhibitory concentration).

Berdasarkan pada penelitian awal yang telah dilakukan diperoleh hasil pengukuran diameter zona hambat yang lebih optimal pada 16 jam pertama dibandingkan dengan pengukuran 24 jam setelah diinkubasi. Oleh karena itu pada penelitian ini pengukuran diameter zona hambat dilakukan hanya pada 16 jam setelah inkubasi.

Hasil pengukuran pada 16 jam setelah inkubasi menunjukkan bahwa ekstrak daun putri malu menghambat pertumbuhan ke lima jenis bakteri uji dengan terlihat adanya zona hambat di sekitar sumur media uji. Penghambatan ini pada ke lima jenis bakteri dimulai pada konsentrasi yang berbeda-beda yaitu pada bakteri Enterobacter cloacae mulai dari konsentrasi 33\% (Tabel 2), Pseudomonas aeuruginosa dan Proteus stuarti pada konsentrasi 50\% (Tabel 1 dan 5), sedangkan Escherichia coli dan Staphylococcus aureus hanya pada konsentrasi 100\% (Tabel 3 dan 4). Selain itu, hasil pengukuran diameter zona hambat menunjukkan juga bahwa efek antimikroba ekstrak daun putri malu ternyata makin meningkat dengan adanya peningkatan konsentrasi larutan uji. Hal ini menunjukkan bahwa terdapat hubungan antara dosis dengan efek anti-mikroba ekstrak daun putri malu terhadap kelima jenis bakteri uji.

Berdasarkan pada ukuran rata-rata diameter zona hambat terbesar yang terbentuk pada sekitar sumur media uji, maka bakteri yang paling sensitif terhadap ekstrak daun putri malu secara berurutan adalah Enterobacter cloacae, Pseudomonas aeruginosa, Proteus stuarti, Escherichia coli, dan Staphylococcus aureus.

Akuades yang digunakan sebagai kontrol negatif dari hasil penelitian ini tidak memperlihatkan adanya zona hambat yang terbentuk, sedangkan larutan antibiotik sebagai pembanding terhadap ekstrak daun putri malu memiliki diameter rataan terbesar.

Hasil penelitian ini menunjukkan bahwa ekstrak daun putri malu memiliki efek antimikroba terhadap ke lima jenis bakteri uji. Walaupun demikian ekstrak ini belum dapat diaplikasikan pada pengobatan antimikroba karena masih diperlukan penelitian lanjut untuk mengetahui efek samping dan efek toksik melalui pengujian pada hewan coba. Juga diperlukan pengujian kemampuan antimikroba dari ekstrak daun putri malu terhadap mikroba lainnya.

Kemampuan dan mekanisme kerja ekstrak daun putri malu dalam menghambat 
pertumbuhan bakteri masih belum di-pahami dengan jelas. Untuk itu masih diperlukan penelitian lanjut tentang mekanisme kerja efek antimikroba dari ekstrak daun putri malu dan bagian-bagian lainnya dari tanaman ini yang diharapkan dapat membuahkan hasil yang bermanfaat bagi manusia.

\section{KESIMPULAN}

Hasil penelitian memperlihatkan bahwa ekstrak daun putri malu memiliki daya antimikroba terhadap ke lima jenis bakteri uji yaitu: Pseudomonas aeruginosa, Enterobacter cloacae, Staphylococcus aureus, Proteus stuarti dan Escherichia coli. Efek antimikroba ekstrak ini ternyata makin meningkat dengan adanya peningkatan konsentrasi larutan uji yang menunjukkan terdapatnya hubungan antara dosis dengan efek antimikroba ekstrak daun putri malu terhadap ke lima jenis bakteri uji.

\section{SARAN}

Perlu diadakan pengujian efek antimikroba dari ekstrak daun putri malu terhadap bakteri lainnya dan penelitian lanjut dengan menggunakan hewan coba untuk menguji keefektifan, disamping memantau terjadinya efek samping dan efek toksik dari ekstrak tersebut. Penelitian lanjut dengan menggunakan bagian-bagian lain dari tanaman putri malu untuk membandingkan efek antimikroba dari masing-masing bagian tersebut diharapkan akan membuka wawasan baru mengenai penggunaannya dalam pengobatan klinis.

\section{DAFTAR PUSTAKA}

1. Obat tradisional. Dari Wikipedia Indonesia, ensiklopedia bebas berbahasa Indonesia. [homepage on the Internet]. 2009 [cited 4 April 2009] Available from URL:http://id.wiki-pedia.org/wiki/ obat tradisional..

2. Sardjono H. Penggunaan obat tradisional. Cermin Dunia Kedokteran. [homepage on the Internet]. Nodate [cited 12 Mei 2009]. Available from URL: http://www. kalbe.co.id.

3. Djauhariya, Hernani. Gulma berkhasiat obat. Jakarta: Penerbit Penebar Swadaya, 2004. Hal. 127.

4. Suyatna N. Kearifan tradisional masyarakat selamatkan tumbuhan obat. [homepage on the Internet]. Nodate [cited 12 Mei 2009]. Available from URL: http://racik. word press.com.

5. Elvira R. Wetland di daerah tungkaran. [homepage on the Internet]. Nodate [cited 28 April 2009]. Available from URL: http://ochasblog. blogspot.com/ 2009/03/ wetland-di-daerah-tungkaran. html

6. Wijayakusuma HMH. Bebas penyakit ginjal dan saluran kemih. Cetakan Pertama. Jakarta: Pustaka Bunda, 2008. Hal.64. 